\title{
O ESPAÇO VIVIDO E A PEDAGOGIA SITUADA DE PAULO FREIRE
}

Enio Serra

Resumo

O conhecimento sobre a realidade sociocultural dos educandos, bem como a maneira com que estes a interpretam é uma das principais características da pedagogia freiriana. Em função disso, no processo de construção da práxis pedagógica libertadora, as localidades onde vivem os estudantes precisam ser objeto de investigação por parte dos educadores e educadoras com vistas à definição de temas geradores do conhecimento escolar. Com base nessa perspectiva, o presente artigo tem como objetivo refletir sobre as possibilidades analíticas acerca da realidade vivenciada pelos educandos tendo como pressuposto básico a espacialidade inerente à existência humana. Para tanto, o ensaio estabelece o conceito de espaço vivido como eixo através do qual outras categorias e noções espaciais são abordadas em consonância com os princípios da dialogicidade e da problematização, ambos próprios da concepção de educação preconizada por Paulo Freire. As reflexões e análises têm como base algumas obras do autor, assim como referências de pesquisadores vinculados principalmente ao conhecimento geográfico. Como principais contribuições para práticas pedagógicas emancipadoras, argumenta-se a favor da necessidade de se criar procedimentos metodológicos que possibilitem o levantamento de informações sobre o contexto socioespacial onde o projeto educativo está inserido e promovam a escuta ativa sobre o que os educandos e outros agentes sociais que atuam na localidade têm a dizer sobre suas vivências e práticas socioespaciais.

Palavras-chave: espaço vivido; lugar; pedagogia situada; educação popular; práxis pedagógica.

\section{THE LIVED SPACE AND PAULO FREIRE'S SITUATED PEDAGOGY}

\begin{abstract}
Knowledge about the sociocultural reality of students, as well as the way they interpret it, is one of the main characteristics of Freire's pedagogy. As a result, in the process of building the liberating pedagogical praxis, the places where students live need to be the object of investigation by educators with a view to defining themes that generate school knowledge. Based on this perspective, this article aims to reflect on the analytical possibilities about the reality experienced by students having as a basic assumption the spatiality inherent to human existence. Therefore, the essay establishes the concept of lived space as an axis through which other categories and spatial notions are approached in tandem with the principles of dialogicity and problematization, both typical of the concept of education advocated by Paulo Freire. The reflections and analyzes are based on some of the author's works, as well as references from researchers mainly linked to geographic knowledge. As main contributions to emancipatory pedagogical practices, it is argued in favor of the need to create methodological procedures that enable the collection of information about the socio-spatial context where the educational project is inserted and promote active listening to what students and other social agents do that work in the locality have to say about their experiences and socio-spatial practices.
\end{abstract}

Keywords: lived space; place; situated pedagogy; popular education; pedagogical praxis. 


\section{EL ESPACIO VIVIDO Y LA PEDAGOGÍA SITUADA DE PAULO FREIRE}

\section{Resumen}

El conocimiento de la realidad sociocultural de los estudiantes, así como la forma en que la interpretan, es una de las principales características de la pedagogía de Freire. En consecuencia, en el proceso de construcción de la praxis pedagógica liberadora, los lugares donde viven los estudiantes deben ser objeto de investigación por parte de los educadores con miras a definir temas que generen conocimiento escolar. A partir de esta perspectiva, este artículo pretende reflexionar sobre las posibilidades analíticas sobre la realidad vivida por los estudiantes teniendo como presupuesto básico la espacialidad inherente a la existencia humana. Para hacer eso, el ensayo establece el concepto de espacio vivido como eje a través del cual se abordan otras categorías y nociones espaciales en línea con los principios de dialogicidad y problematización, ambos propios del concepto de educación defendido por Paulo Freire. Las reflexiones y análisis se basan en algunos de los trabajos del autor, así como en referencias de investigadores principalmente vinculados al conocimiento geográfico. Como principales aportes a las prácticas pedagógicas emancipadoras, se argumenta a favor de la necesidad de crear procedimientos metodológicos que permitan la recolección de información sobre el contexto socioespacial donde se inserta el proyecto educativo y promuevan la escucha activa de lo que los estudiantes y otros agentes sociales locales tienen que decir sobre sus vivencias y prácticas socioespaciales.

Palabras clave: espacio vivido; lugar; pedagogía situada; educación popular; praxis pedagógica.

A localidade dos educandos é o ponto de partida para o conbecimento que eles vão criando no mundo. "Seu" mundo em última análise é a primeira e inevitável face do mundo mesmo.

Paulo Freire

\section{INTRODUÇÃO}

A escrita do presente artigo foi impulsionada por fatores de diferentes ordens. O primeiro deles diz respeito ao próprio centenário de Paulo Freire comemorado neste ano de 2021. Junto às ideias aqui desenvolvidas segue uma sincera homenagem e um profundo agradecimento a esse intelectual que tem inspirado cada dia de nossa jornada profissional e humana. Um segundo fator se refere ao momento crítico e delicado que atravessa a educação brasileira. Entendemos que uma das formas de enfrentar $\mathrm{o}$ ataque conservador e neoliberal às perspectivas pedagógicas progressistas e libertadoras é pôr em destaque a vivacidade e a atualidade da práxis freiriana. Por fim, como desejo antigo e relacionado a práticas educativas que adotam princípios da educação popular, o principal fator que move este ensaio é a necessidade de se refletir sobre a espacialidade da existência humana e sua relação com o processo de construção do conhecimento.

Em função disso, as reflexões partem do olhar de um profissional da educação geográfica, o que não significa de modo algum que o artigo se dirige exclusivamente a educadores dessa área. Pelo contrário, a intenção é socializar o olhar geográfico como contribuição para possíveis interpretações da obra de Paulo Freire e estimular o diálogo com outras áreas do conhecimento. Nesse sentido, embora o foco das reflexões esteja principalmente voltado para as práticas curriculares, há também importante colaboração para a gestão de escolas e de projetos educativos em diferentes níveis e modalidades de ensino.

A epígrafe do artigo (FREIRE, 1992, p. 86) revela o quanto o contexto espacial dos educandos está presente e marca profundamente o pensamento pedagógico de Freire. Nesse 
fragmento, as palavras localidade e mundo expressam tal contexto e afirmam o papel da espacialidade no processo de construção do conhecimento escolar. No entanto, é importante a indagação sobre os significados que tais palavras podem obter quando se quer compreender mais a fundo os sentidos da pedagogia libertadora. A localidade seria apenas um ponto qualquer situado no espaço de uma cidade ou do campo? Mundo estaria relacionado somente à vastidão da superfície terrestre? Ou ele se referiria também aos locais e a tudo que conhecemos ao longo de nossas vidas, o "nosso" mundo? Considerando a riqueza e a profundidade dessa frase, acreditamos o quanto ela é vigorosa para a compreensão da concepção de educação proposta por Freire e o quanto seria necessário destrinchá-la e depurá-la à luz de conceitos e categorias desenvolvidos por pesquisadores e pensadores da Geografia e de outras ciências humanas que têm o espaço como foco de interesse.

Assim, o presente ensaio tem como objetivo refletir sobre as diversas possibilidades analíticas acerca da realidade vivenciada pelos educandos. Para isso, estabelece o conceito de espaço vivido como eixo através do qual outras categorias e noções espaciais são abordadas em consonância com os princípios da dialogicidade e da problematização, ambos próprios da pedagogia freiriana.

Inicialmente, o espaço vivido é abordado tendo como referência a necessidade do diálogo na prática político-pedagógica. Nesse ponto, a pedagogia situada de Freire, aquela que parte da compreensão do educando sobre sua realidade e caminha em direção a uma compreensão crítica e científica dessa mesma realidade (FREIRE e SHOR, 1986), é caracterizada em seus principais fundamentos. Em seguida, o princípio da problematização é analisado junto a alguns conceitos espaciais com o intuito de aprofundar a compreensão dos preceitos básicos da concepção popular de educação, revelada aqui em uma necessária pedagogia da pergunta (FREIRE e FAUNDEZ, 1985) que pode levar a uma verdadeira pedagogia do direito à educação (FÁVERO, 2007).

\section{ESPAÇO VIVIDO E DIALOGICIDADE FREIRIANA}

Freire afirmava que o diálogo faz parte da natureza histórica dos seres humanos e que, por esse motivo, ele não pode ser considerado apenas como uma técnica ou uma tática dos educadores (FREIRE e SHOR, 1986) ${ }^{1}$. Para ele, a dialogicidade é uma posição epistemológica que compõe a própria construção do conhecimento, uma vez que se encontra presente na conexão entre a cognoscibilidade do educador e a cognoscibilidade do educando. Seu pensamento entende que o "objeto a ser conhecido, num dado lugar, vincula esses dois sujeitos cognitivos, levando-os a refletir juntos sobre o objeto. O diálogo é a confirmação conjunta do professor e dos alunos no ato comum de conhecer e reconhecer o objeto de estudo." (FREIRE e SHOR, 1986, p. 65) Sendo assim, não há a transferência estática de conhecimento, mas uma aproximação dinâmica entre educador e educando em direção ao objeto.

Tal dinamicidade, o movimento mesmo do diálogo, se dá nas diferentes dimensões da construção do conhecimento, inclusive na própria definição do objeto a ser estudado, isto é, dos temas e tópicos do conhecimento escolar a serem considerados na programação curricular. É isso que Freire quer dizer quando afirma que a "inquietação em torno do conteúdo do diálogo é a inquietação em torno do conteúdo programático da educação" (FREIRE, 1987, p. 85). A

\footnotetext{
1 A obra Medo e ousadia: o cotidiano do professor (FREIRE e SHOR, 1986) foi escrita a partir de diálogos entre Paulo Freire e Ira Shor, sendo as falas de cada um identificáveis ao longo do texto. As citações indiretas ou diretas desta obra aqui utilizadas são exclusivamente referentes às falas proferidas por Paulo Freire.
} 
inquietação a que se refere tem a ver com a busca pelos temas, assim como tem a ver com a investigação sobre o universo temático dos educandos, este composto por uma variedade de elementos, dentre os quais a localidade onde a escola se insere e/ou onde os educandos vivem.

Como nesse universo temático se encontram os temas geradores, isto é, temas que se desdobram em outros tantos temas, investigá-lo seria, na verdade, investigar os próprios temas geradores. No entanto, Freire alerta que os temas geradores só podem ser compreendidos nas relações homens-mundo e investigá-los significa acessar "O pensar dos homens referido à sua realidade, é investigar seu atuar sobre a realidade, que é sua práxis." (FREIRE, 1987, p. 98) Como toda realidade e toda práxis só existem a partir de uma base espaçotemporal, tal investigação precisa considerar a espacialidade e a temporalidade desses sujeitos. Nesse sentido, a localidade pode ser interpretada como o espaço e o tempo vividos pelos educandos e os temas geradores como originários da percepção que eles constroem sobre suas ações e experiências vividas nessa localidade.

Ao nos deparamos com essas afirmações, podemos nos perguntar sobre a maneira com que devemos proceder para realizar a investigação dos temas geradores. Diante de tantas dificuldades vivenciadas em escolas e em outros contextos educativos, nos indagamos sobre a possibilidade real dessa prática pedagógica. Em primeiro lugar, é preciso considerar que talvez não consigamos desenvolvê-la em sua totalidade se não contarmos com o apoio administrativo e pedagógico da gestão escolar. De qualquer forma, o exercício epistemológico que essa perspectiva impõe é válido e possível de ser feito. Para isso, é necessário compreendermos a fundo o que significa a "realidade" dos educandos, o que faz parte de seu universo temático e que experiências vivenciam nos lugares em que moram, trabalham, circulam. Acreditamos que, nessa direção, o conceito de espaço vivido e todo o debate em torno das relações entre lugar, território, cotidiano, saberes e práticas espaciais podem contribuir para o início do processo, ou seja, para que se possa vislumbrar diferentes possibilidades de interpretação sobre a realidade, a localidade, o "mundo" em que vivem os educandos.

O conceito de espaço vivido surge com o geógrafo francês Armand Frémont, nos anos 1970, e diz respeito à dimensão do espaço geográfico apreendida simbólica, cultural e afetivamente pelas pessoas em suas práticas sociais cotidianas. É, portanto, uma experiência que produz e é produzida por valores, constrói sentidos e imagens em relação aos lugares, além de possibilitar diferentes formas de interpretação sobre os acontecimentos e configurações espaciais que caracterizam as cidades, as áreas rurais, as florestas etc. Para Frémont (1980, p. 23), "as relações do homem com o espaço não constituem um feixe de dados imanentes ou inatos; combinam-se numa experiência vivida que, de acordo com as idades da vida, se forma, se estrutura, se desfaz". Há, assim, segundo suas proposições, uma psicologia do espaço que se transforma ao longo do tempo de vida das pessoas. Esse é um dos sentidos do vínculo entre espaço e tempo e faz com que, no trabalho pedagógico, as faixas de idade precisem ser consideradas na forma com que os educandos percebem os lugares.

De acordo com Claval (2003), as formulações de Frémont nos apresentam duas importantes direções: a atenção dada à forma com que as pessoas se exprimem e a compreensão do significado que a experiência dos lugares adquire para os seus habitantes. Contudo, se o espaço vivido representa essa experiência particular e subjetiva, ele não seria marcado pelas condições materiais de vida e pelas classes sociais dos sujeitos? Frémont não aprofunda essa questão, mas parece não desconsiderá-la de todo, uma vez que, ainda segundo Claval (2003), sua noção de espaço vivido se refere ao contexto em que a significação da experiência se desenvolve.

Examinando melhor a questão, podemos entender que nossa percepção dos lugares é vinculada às condições de vida e ao contexto socioespacial em que estamos inseridos. Assim, 
como atesta Damiani (2019, p. 151), “[a] interpretação do mundo e a realidade social envolvida não são esferas separadas, depois reunidas, na separação, sob o privilégio do pensamento". Percebemos e sentimos os lugares de acordo com as condições dadas e, por esse motivo, é fundamental levarmos em conta as desigualdades sociais e a segregação socioespacial características da sociedade capitalista. É isso que faz com que, por exemplo, moradores de favelas e das periferias urbanas tenham uma percepção distinta da cidade daqueles que habitam bairros de elite ou de classe média. E é esse o sentido de universo temático dado por Freire ao afirmar que é o pensamento-linguagem dos educandos referido à realidade que os educadores devem investigar. Em outras palavras, são nos níveis de percepção da realidade e nas visões de mundo daí constituídas que os temas geradores se encontram envolvidos (FREIRE, 1987).

Trazendo para a reflexão a dimensão do conceito de lugar como espaço vivido, ou "como porção do espaço apropriável para a vida" (CARLOS, 2007, p. 17), fica claro, então, como os lugares nos afetam, positiva e negativamente, ou seja, como o que somos, o que pensamos e as ideias que construímos sobre as coisas da vida dependem, em grande medida, do contexto socioespacial em que vivemos. Nossas memórias individuais e coletivas são, muitas vezes, pautadas por acontecimentos que nos marcam profundamente, nos fazendo repelir ou nos sentirmos atraídos pelos lugares onde ocorreram. Isso demonstra o quanto as relações simbólicas que mantemos com o espaço partem de nossas vivências e dos valores e culturas nos quais estamos imersos. Dessa forma, como afirma Damiani (2019, p. 154), descobrimos que "o espaço não é uma coisa separada de nós, nele projetamos nossa personalidade e a ele somos ligados por limites emocionais. Ele é vivido. Fala-se em geograficidade, como experiência que temos dos ambientes, parte inevitável de nossa consciência do mundo vivido." É nesse sentido que, na pedagogia dialógica, o lugar, o espaço vivido e a geograficidade dos educandos precisam ser evocados como possibilidades de problematização e de construção do conhecimento a partir de temas geradores.

Em espaços urbanos, por exemplo, é importante nos indagarmos sobre como as condições objetivas dos lugares são subjetivamente vividas pelos diferentes agentes produtores do espaço (SERPA, 2011). Considerando os bairros como espaços vividos e sentidos, Serpa (2011, p. 105) chama a atenção, por exemplo, para o fato de que "é preciso reconhecer os espaços populares das metrópoles como centrais para o cotidiano e a vida [...] assumindo o princípio de que todos os lugares são centralidades potenciais [...]." Com isso, podemos compreender a centralidade das favelas para seus moradores e superar a visão de que elas são apenas territórios periféricos onde prevalecem as injustiças sociais, a destituição de direitos e onde aparentemente o Estado não se faz presente. Na percepção daquelas e daqueles que nelas vivem, as favelas são também territórios de sobrevivência, de solidariedade, de produção cultural e de saberes, isto é, "longe de representarem territórios caóticos, sem lei e sem controle, que ameaçam a cidade - como afirmam os discursos mais conservadores - as favelas [...] são, na verdade, uma das expressões de maior vitalidade da vivência cotidiana dos pobres, em um permanente processo de ressignificar a cidade.” (BARBOSA e SILVA, 2013, p. 125) E é a partir dessas percepções e formas de sentir os lugares que experiências se constituem e saberes são construídos. Um saber de tipo local, territorial. Uma das dimensões do saber da experiência feito, sobre o qual nos fala Freire (1992).

Isso acontece porque, como já dito, "Os seres humanos são espaciais em sua essência, e [...] viver é produzir/experienciar espaços” (SERPA, 2017, p. 587). Sendo assim, é possível afirmarmos que o saber construído cotidianamente a partir das experiências de vida têm um largo lastro espacial, ou seja, se constituem em saberes sobre/com/no/do espaço vivido. Como os lugares possuem algo de particular, embora também apresentem elementos comuns e, muitas 
vezes, subordinados a outros lugares, os saberes neles constituídos são essencialmente locais. São, então, saberes oriundos de práticas espaciais, ou práticas-baseadas-no-lugar (SAQUET, 2019), que revelam, por exemplo, o pertencimento a um grupo ou classe social.

Para a perspectiva dialógica de educação que tenha como horizonte a emancipação intelectual dos educandos, é preciso reconhecer e conhecer esses saberes. É com eles e a partir deles que o conhecimento escolar sistematizado, de base científica, filosófica e artística deve ser selecionado e desenvolvido pedagogicamente. Portanto, quando Freire (1994, p. 86) afirma que "[a] localidade dos educandos é o ponto de partida para o conhecimento que eles vão criando no mundo", é esse saber local e o contexto socioespacial em que ele é produzido que devem ser os objetos de investigação, análise e de construção do conhecimento. Nesse sentido, é importante que a equipe de direção, coordenação e docentes pesquisem sobre o lugar em que atuam, tentem identificar as características históricas e socioambientais daquela localidade, seus principais problemas etc. Junto a esse levantamento, é igualmente importante ouvir a comunidade sobre o que pensam em relação ao bairro/localidade, suas histórias de vida, a interpretação que dão aos problemas que enfrentam, às ações que desenvolvem, às organizações e movimentos sociais e culturais ali instituídos. É com base na análise desse mapeamento que a equipe pedagógica pode iniciar o processo de diálogo para a construção significativa do conhecimento escolar. De acordo com Freire, é assim também que os educadores se sentem educadores-educandos, pois, além de se descobrirem como intelectuais da educação, se veem como seres inconclusos e em permanente processo de aprendizagem.

No entanto, muitos profissionais da educação têm dúvidas quanto ao seu papel na pedagogia situada e dialógica que nos apresenta Paulo Freire. Se a esses profissionais cabe o domínio de temas e conteúdos de ensino duramente aprendidos nos cursos de formação inicial e nos exaustivos processos de preparação de aulas, como e por que teriam que ficar restritos ao saber popular local? Em função dessa problemática interpretação, Freire foi, por diversas vezes, acusado de promover uma perspectiva pedagógica que bloquearia o acesso e a socialização do conhecimento de base científica aos educandos das classes populares. Em Pedagogia da esperança (1992), obra em que revisita suas ideias divulgadas décadas antes em Pedagogia do oprimido (1987), um de seus trabalhos pioneiros e talvez o mais conhecido no mundo, ele retoma essa questão e afirma que "partir do saber que os educandos tenham não significa ficar girando em torno deste saber. Partir significa pôr-se a caminho, ir-se, deslocar-se de um ponto a outro e não ficar, permanecer [...] Partir do saber de 'experiência feito' para superá-lo não é ficar nele" (FREIRE, 1992, p. 70-71, grifos do autor). Aprofundando a epistemologia dialógica da construção do conhecimento, ele ainda assinala:

O que tenho dito sem cansar, e redito, é que não podemos deixar de lado, desprezado como algo imprestável, o que educandos, sejam crianças chegando à escola ou jovens e adultos a centros de educação popular, trazem consigo de compreensão do mundo, nas mais variadas dimensões de sua prática na prática social de que fazem parte. Sua fala, sua forma de contar, de calcular, seus saberes em torno do chamado outro mundo, sua religiosidade, seus saberes em torno da saúde, do corpo, da sexualidade, da vida, da morte, da força dos santos, dos conjuros. (FREIRE, 1992, p. 86)

Acrescentando a esses saberes aqueles voltados aos elementos da natureza e aos aspectos sociais dos lugares, reforçamos a ideia de que considerar esses saberes nunca significou fixar-se em torno deles e jamais extrapolá-los, assim como nunca significou permanecer na localidade, no 
espaço vivido, sem oportunizar o acesso a outros lugares, a outros territórios, a outras possibilidades de compreensão do mundo. Até porque Freire deixa claro que superar os saberes locais, sem negá-los, é um direito dos trabalhadores populares, caso contrário seria "como se desvelar a razão de ser das coisas e ter delas um conhecimento cabal fosse ou devesse ser privilégio das elites" (FREIRE, 1992, p. 84). Definitivamente, a pedagogia situada e dialógica nunca se prestou a esse papel. Oposta a isso, sempre defendeu a emancipação intelectual e a construção do saber autônomo das classes populares através da apropriação do conhecimento universal sistematizado.

Ao relacionarmos o princípio da dialogicidade ao conceito de espaço vivido, podemos compreender o quão rico é o universo temático dos educandos e o quanto uma infinidade de temas geradores pode dele emergir. $\mathrm{Na}$ continuidade do processo pedagógico para além da seleção curricular, resta pensarmos sobre as questões que envolvem a abordagem didática dada ao conhecimento escolar e sua vinculação ao saber local de experiência feito. Mais uma vez, acreditamos que a análise espacial contribui para a compreensão dessa perspectiva.

\section{A PROBLEMATIZAÇÃO DO MUNDO NA BUSCA DO SER MAIS}

$\mathrm{Na}$ epígrafe desencadeadora e provocativa do presente artigo, Freire afirma que, em última análise, o mundo do educando "é a primeira e inevitável face do mundo mesmo." (FREIRE, 1992, p. 86). Com isso, nos estimula a pensar sobre o significado da palavra mundo e sua compreensão à luz dos conceitos de lugar e espaço vivido. Como o ser humano percebe o mundo? Para Carlos (2007, p. 17) "é através de seu corpo, de seus sentidos que ele constrói e se apropria do espaço e do mundo." Se é assim, o mundo, entendido como uma infinidade de fenômenos e relações entre diferentes lugares, é percebido através do lugar, ou seja, do espaço onde se vive, se sente, se respira o ar. Onde, portanto, o corpo capta as sensações e a mente constrói, na relação com a natureza e com outros seres humanos, as ideias, visões, saberes, a inteligibilidade. Dessa forma, é possível dizer que o lugar contém o mundo.

Por essa razão, Freire alerta para o fato de que "assim como é errado ficar aderido ao local, perdendo-se a visão do todo, errado é também pairar sobre o todo sem referência ao local de onde se veio". (FREIRE, 1992, p. 87-88) Tal assertiva encontra eco na ideia de que "[c]ada lugar é, à sua maneira, o mundo. [...] Mas, também, cada lugar, irrecusavelmente imerso numa comunhão com o mundo, torna-se exponencialmente diferente dos demais." (SANTOS, 1996a, p. 252) Aqui, temos um jogo de representações em que o mundo se refere ao todo, à totalidade que interliga e integra os fenômenos, as ações políticas, econômicas, simbólicas, enquanto o lugar expressa a particularidade, o que é único, o que é próprio, o imponderável. Nesse sentido, o todo, ou o mundo, só é possível a partir da relação/integração das partes, dos lugares. Contudo, tal relação não é simétrica, já que os lugares exercem papéis diferentes nessa integração e uns possuem mais poder do que outros. É o que Santos (1996a) revela quando afirma que os centros de poder, ou seja, os centros de decisão das ações globais se encontram em poucos lugares do planeta. Dessa forma, fica evidente a existência de "um conflito que se agrava entre um espaço local, espaço vivido por todos os vizinhos, e um espaço global, habitado por um processo racionalizador e um conteúdo ideológico de origem distante e que chegam a cada lugar com os objetos e as normas estabelecidos para servi-los." (SANTOS, 1996b, p. 18). Isso significa dizer que o bairro e a cidade em que vivemos podem ser (e são) invariavelmente impactados por decisões tomadas em lugares muito distantes, muitas vezes com o intuito de atender os interesses dos agentes que comandam as ações globais, em geral grandes corporações empresariais, e pouco ou nada beneficiam a população local. 
A compreensão desse processo, no entanto, não se faz completa se não considerarmos que atualmente essa relação assimétrica entre os lugares se dá em forma de rede. Isso se deve graças aos progressos técnicos que possibilitaram deslocamentos mais rápidos e comunicação instantânea como nunca se viu antes. Além disso, e exatamente por isso, a realização da vida econômica tem se dado cada vez mais através de redes globais, cuja noção se impõe no tempo presente (SANTOS, 1996a). Na verdade, é isso que caracteriza o processo de globalização em seus vários aspectos (econômicos, culturais, sociais) e confere a ideia de um espaço global ou, como prefere Santos (1996a), de espaços da globalização. Isso porque, sob sua perspectiva, não há espaço global, mas espaços mundializados integrados por redes, o que faz com que cada lugar seja, simultaneamente, "objeto de uma razão global e de uma razão local, convivendo dialeticamente” (SANTOS, 1996a, p. 273).

Nesse contexto, o lugar - sempre correlacionado à esfera do espaço vivido - passa por redefinições em função de seu pertencimento a uma rede de lugares. Para Carlos (2007, p. 21), é "evidente que o lugar se define, inicialmente, como a identidade histórica que liga o homem ao local onde se processa a vida, mas cada vez mais a 'situação' se vê influenciada, determinada, ou mesmo ameaçada, pelas relações do lugar com um espaço mais amplo." Nesse sentido, o entendimento de uma pedagogia situada passa necessariamente pela ideia de que não há mais lugares isolados, pois a globalização alterou o sentido de localização ao mundializar praticamente todos os lugares. Isso, no entanto, não significa a perda de importância do lugar, pois, ainda de acordo com Carlos (2007, p. 22):

O lugar se produz na articulação contraditória entre o mundial que se anuncia e a especificidade histórica do particular. Deste modo, o lugar se apresentaria como o ponto de articulação entre a mundialidade em constituição e o local enquanto especificidade concreta, enquanto momento. É no lugar que se manifestam os desequilíbrios, as situações de conflito e as tendências da sociedade que se volta para o mundial.

Nessa direção, tal perspectiva faz com que, segundo Massey (2000), o espaço vivido seja considerado como lugar de encontro, uma vez que sua construção depende da ligação com outros lugares. Para a autora, o lugar é o resultado de uma constelação de relações sociais que se entrelaçam de modo muito particular, o que o faz ser visto como ponto único dessa interseção e dá a ele um sentido global.

Dito isto, o desafio posto para os educadores e educadoras progressistas, que acreditam na concepção popular e no poder transformador da educação, é identificar e analisar tanto as características particulares da localidade em que atuam quanto aquelas que se originam de outros processos. A essa ação cabe, então, desvelar as decisões de âmbito nacional e de caráter global que impactam a localidade, além de indagar sobre os interesses que elas atendem e os grupos e classes sociais beneficiados.

Na práxis pedagógica, isso só é possível a partir do princípio da problematização, o que, em certa medida, significa assumir a natureza política da educação. Tomá-lo como referência pode promover, por exemplo, a desnaturalização das desigualdades, das relações de poder e o estranhamento da realidade vivida, além de pôr em xeque padrões socioculturais opressores e tornar possível a idealização de outras perspectivas de vida em sociedade. $\mathrm{Na}$ busca pela realização do caráter emancipador do processo pedagógico, Freire (1987) lembra, porém, que o importante para a educação problematizadora é que homens e mulheres submetidos à dominação lutem por sua emancipação. Por isso, é preciso e imprescindível problematizar o mundo. Nessa 
perspectiva, o mundo - nele incluídos os lugares, o espaço vivido - “já não é algo sobre o que se fala com falsas palavras, mas o mediatizador dos sujeitos da educação, a incidência da ação transformadora dos homens, de que se resulte a sua humanização.” (FREIRE, 1987, p. 75) Assim, a construção de conhecimento só se faz significativa se mediatizada pelo espaço vivido e pelas relações que se estabelecem em rede entre os lugares.

No entanto, para ser efetivada, a problematização mediatizada pelas coisas da vida necessita de abordagens didáticas, de metodologias que a garantam no ato de aprender-ensinar. Sobre isso, Freire nos chama a atenção para o valor da postura indagativa que se traduz em uma verdadeira pedagogia da pergunta. Para ele, a raiz da transformação do mundo é a radicalidade do ato de perguntar sobre a existência humana (FREIRE e FAUNDEZ, p. 27). Sendo assim, é fundamental que a pergunta seja estimulada, valorizada e esteja sempre presente como prática cotidiana nas situações de aprendizagem. Afinal, só se aprende a perguntar praticando a pergunta sem medo. Mas, Freire alerta que a preocupação em torno do ato de perguntar não pode se restringir ao nível da pergunta pela pergunta. Problematizando a relação entre pergunta e resposta, Freire associa esse processo à ideia de práxis, isto é, à perspectiva da ação-reflexão-ação. Segundo ele:

O importante, sobretudo, é ligar, sempre que possível, a pergunta e a resposta a ações que foram praticadas ou a ações que podem vir a ser praticadas ou refeitas [...] o necessário é que o educando, ao perguntar sobre um fato, tenha na resposta uma explicação do fato e não a descrição pura das palavras ligadas ao fato. É preciso que o educando vá descobrindo a relação dinâmica, forte, viva, entre palavra e ação, entre palavra-ação-reflexão. (FREIRE e FAUNDEZ, p. 26)

Para que educadores e educadoras incentivem estudantes a praticarem perguntas que levem ao estranhamento do espaço vivido, por exemplo, é fundamental que eles mesmos também desenvolvam a postura indagativa. Como questões iniciais sobre a práxis pedagógica, talvez seja importante perguntarem a si mesmos e ao coletivo docente como se processa a relação entre saber popular e conhecimento científico e quais seriam as práticas dialógicas necessárias para a realização de um currículo de fato participativo (SCOCUGLIA, 2005). Outro conjunto de indagações pode se referir à localidade em que atuam para que, junto aos educandos, problematizem, por exemplo, as relações de poder ali estabelecidas, os fatores naturais e humanos que interferem na dinâmica e nas feições de rios e morros da região, a reconstrução da história do lugar, além das dimensões biológica, simbólica e social dos corpos humanos que ali vivem.

Dessa forma, é imprescindível que o princípio da problematização, assim como o princípio da dialogicidade, sustente tanto as metodologias utilizadas quanto os conteúdos da programação curricular. Nesse processo, ambos "devem estar contextualizados e influenciados pela cultura e pelas experiências de vida dos atores educacionais que estão envolvidos nessa construção, a saber: educandos, educadores, gestores, pais, comunidade educativa." (SCOCUGLIA, 2005, p. 82) Esse fazer representa a incessante busca pelo ser mais e requer um projeto coletivo, já que tal busca não se realiza "no isolamento, no individualismo, mas na comunhão, na solidariedade dos existires, daí que seja impossível dar-se nas relações antagônicas entre opressores e oprimidos.” (FREIRE, 1987, p. 75).

Problematizar o mundo em busca do ser mais significa, portanto, não só conceber o lugar em que vivemos como fruto de nossas ações e relações afetivas sobre ele, mas também como 
produto de um feixe de influências advindas de outros cantos do planeta. Significa também problematizar práticas originadas tanto de saberes da experiência quanto do conhecimento científico com o objetivo de "superar seus limites epistemológicos, políticos e éticos, visando transformações históricas humanizadoras, solidárias, que direcionem a inconclusão da vida humana para a busca de um ser mais" (SAUL e SILVA, 2014, p. 2.072). É assim que a busca do ser mais, para Freire (1987), representa a busca pela humanização dos homens e mulheres.

\section{CONSIDERAÇÕES FINAIS}

Em tempos atravessados pela ascensão de projetos conservadores que pregam a negação da realidade por meio do ainti-intelectualismo e da veiculação de informações e notícias falsas, tem sido difícil promover o pensamento autônomo, crítico e criativo nas escolas. O projeto neoliberal e privatista de educação, embora partindo de outras premissas, também contribui com essa situação ao impor uma política de currículo - a Base Nacional Comum Curricular (BNCC) - que tenta uniformizar a seleção de temas e conteúdos disciplinares para todo o país e em todos os níveis e modalidades de ensino. Diante desse contexto, reafirmar a pedagogia situada e libertadora de Paulo Freire representa resistência e luta a favor de uma sociedade em que as classes populares possam vislumbrar outros lugares e mundos possíveis. Se a educação sozinha não tem condições de proporcionar a realização desse projeto, sua colaboração, no entanto, não pode ser dispensada.

Para os profissionais da educação que têm nessa concepção de sociedade seus horizontes político-pedagógicos, a resistência precisa ser traduzida em criatividade para fazer valer aquilo que acreditam estar mais próximo da perspectiva dialógica e problematizadora. Para tanto, é necessário desenvolver metodologias que possibilitem, por exemplo, o mapeamento e levantamento de dados sobre o contexto socioespacial das localidades em que atuam. Além disso, os procedimentos metodológicos precisam prever atividades que promovam o debate e a escuta ativa sobre o que os educandos e outros agentes sociais locais têm a dizer sobre suas vivências e práticas socioespaciais. Dessa forma, o saber local da experiência pode originar temas geradores e ser considerado como eixo através do qual se dá a construção do conhecimento.

A tarefa não é fácil, principalmente quando a prática coletiva é desestimulada e predomina o individualismo competitivo. De qualquer forma, muitas escolas e projetos de educação popular desenvolvem ricas experiências que vão na contramão do que é hegemônico e nos avisam que há possibilidades, que há diferentes maneiras de sermos dialógicos, problematizadores, críticos e criativos. Promover debates com os moradores de uma certa localidade, elaborar o perfil cultural e socioeconômico do público atendido através da análise de dados produzidos por questionários respondidos pelos educandos ou por suas mães/pais/responsáveis, desenvolver estudos sobre a história do bairro através da memória popular, entre outros, são exemplos de ações que muitas unidades escolares e redes públicas de ensino realizam. O material delas obtido pode ser uma grande oportunidade para iniciar a caminhada com a pedagogia situada.

Experimentações, tentativas, ousadia fazem parte da prática docente. Afinal, como nos provoca Freire (1992, p. 155), "ninguém caminha sem aprender a caminhar, sem aprender a fazer o caminho caminhando, sem aprender a refazer, a retocar o sonho por causa do qual a gente se pôs a caminhar". Que nossos passos sejam coerentes com nossos sonhos. Que, inspirados por Freire, consigamos transformar nossas angústias e inseguranças em força e determinação ao longo da caminhada. 


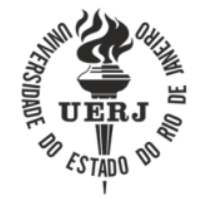

DOI: $10.12957 /$ teias.2021.62401

\section{REFERÊNCIAS}

BARBOSA, Jorge; SILVA, J. S. As favelas como territórios de reinvenção da cidade. Cadernos do Desenvolvimento Fluminense, Rio de Janeiro, n. 1, p. 115-126, fev. 2013. Disponível em: https://www.e-publicacoes.uerj.br/index.php/cdf/article/view/9062. Acesso em: 20 jul. 2018.

CARLOS, Ana Fani A. O lugar no/do mundo. São Paulo: Labur Edições, 2007.

CLAVAL, Paul. A evolução recente da geografia cultural de língua francesa. Geosul, Florianópolis, v. 18, n. 35, p. 7-25, jan. / jun., 2003. Disponível em: https://periodicos.ufsc.br/index.php/geosul/article/view/13599. Acesso em: 06 set. 2021.

DAMIANI, Amélia L. O lugar e o plano do vivido. In: CARLOS, Ana Fani A.; CRUZ, Rita de Cássia A. (orgs.). A necessidade da Geografia. São Paulo: Contexto, 2019. p. 150-162.

FÁVERO, Osmar. O legado de Paulo Freire: passado ou atualidade? REVEJ@ - Revista de Educação de Jovens e Adultos, v. 1, n. 0, p. 1-108, ago. 2007. Disponível em: https://www.usfx.bo/nueva/vicerrectorado/citas/SOCIALES_8/Pedagogia/78.pdf. Acesso em 26 jul. 2021.

FREIRE, Paulo. Pedagogia do oprimido. 17 ed. Rio de Janeiro: Paz e Terra, 1987 [1970].

FREIRE, Paulo. Pedagogia da esperança. Rio de Janeiro: Paz e Terra, 1992.

FREIRE, Paulo; FAUNDEZ, Antonio. Por uma pedagogia da pergunta. Rio de Janeiro: Paz e Terra, 1985.

FREIRE, Paulo; SHOR, Ira. Medo e ousadia: o cotidiano do professor. Rio de Janeiro: Paz e Terra, 1986.

FRÉMONT, Armand. A região, espaço vivido. Coimbra: Almedina. 1980.

MASSEY, Doreen. Um sentido global do lugar. In: ARANTES, Antonio A. (org.). O espaço da diferença. Campinas: Papirus, 2000. p. 176-185.

SANTOS, Milton. A natureza do espaço: técnica e tempo, razão e emoção. São Paulo: Hucitec, 1996 .

SANTOS, Milton. O retorno do território. In: SANTOS, Milton; SOUZA, Maria Adélia A. de; SILVEIRA, Maria Laura (orgs.). Território: globalização e fragmentação. 2 ed. São Paulo: Hucitec; Anpur, 1996b. p. 15-20.

SAQUET, Marco Aurélio. As territorialidades e temporalidades como reciprocidade e práxis popular. In: SAQUET, Marco Aurélio. Saber popular, práxis territorial e contra-begemônica. Rio de Janeiro: Consequência, 2019.

SAUL, Ana M.; SILVA, Antonio Gouvêa da. A matriz de pensamento de Paulo Freire: um crivo de denúncia-anúncio de concepções e práticas curriculares. Revista e-Curriculum, São Paulo, v. 12, n. $03, \quad$ p. 2.064-2.080 out./dez. 2014. Disponível em: https://revistas.pucsp.br/index.php/curriculum/article/view/20907. Acesso em: 09 set. 2018.

SCOCUGLIA, Afonso. As reflexões curriculares de Paulo Freire. Revista Lusófona de Educação, n. 6, p. 81-92, 2005. Disponível em: revistas.ulusofona.pt/index.php/rleducacao/article/view/848. Acesso em: 14 set. 2018.

SERPA, Angelo. Lugar e centralidade em um contexto metropolitano. In: CARLOS, Ana Fani A.; SOUZA, Marcelo L. de; SPOSITO, Maria Encarnação B. (orgs.). A produção do espaço urbano: agentes e processos, escalas e desafios. São Paulo: Contexto, 2011. p. 97-108. 
SERPA, Angelo. Ser lugar e ser território como experiências do ser-no-mundo: um exercício de existencialismo geográfico. Geousp - Espaço e Tempo (Online), v. 21, n. 2, p. 586-600, ago. 2017. Disponível em: http://www.revistas.usp.br/geousp/article/view/125427. Acesso em: 18 ago. 2021.

\section{Informações do autor}

Enio Serra

Universidade Federal do Rio de Janeiro

E-mail: enio.serra@gmail.com

ORCID: https://orcid.org/0000-0001-5372-7439

Link Lattes: http://lattes.cnpq.br/2886910172331641 